\title{
TESTE DE ANTAGONISMO DA MICROBIOTA DO SORO DE QUEIJO COMERCIAIS E COALHADAS PRODUZIDOS DE FORMA ARTESANAIS
}

\author{
Simone Brandão da Silva ${ }^{1}$; Elinalva Maciel Paulo \\ 1. Estágio PEVIC, Graduanda em Bacharelado em Ciências Biológicas, Universidade Estadual de Feira de \\ Santana, e-mail: symoonsea14@gmail.com \\ 2. Orientador, Departamento de Ciências Biológicas, Universidade Estadual de Feira de Santana, e-mail: \\ elinalvamaciel@yahoo.com.br
}

PALAVRAS-CHAVE: Antagonismo bacteriano; soro de leite; microbiota.

\section{INTRODUÇÃO}

O leite é um alimento de grande importância na alimentação devido ao seu elevado valor nutritivo, como fonte de proteínas, lipídios, carboidratos, minerais e vitaminas, sendo por isso considerado um ótimo substrato para o crescimento de vários grupos de microrganismos, desejáveis e indesejáveis (SOUZA et al. 2009; MENEZES et al. 2014). Além dos valores nutricionais, o leite e seus derivados se destacam pela presença de microrganismos benéficos à saúde humana, a exemplo das bactérias lácticas (BAL), onde muitas destas apresentam características probióticas. As bactérias lácticas são comumente utilizadas em processos fermentativos e desempenham um papel fundamental no processo de fermentação do leite e produtos derivados, sendo sua utilização um dos métodos mais antigos de preservação (OUWEHAND; VESTERLUND, 2004; VIEIRA, 2011; FARINHA, 2016), resultado da formação de metabólitos que provavelmente exercem efeitos inibitórios sobre patógenos que acometem o homem e animais.

Diante do exposto, o presente trabalho visa averiguar a presença de metabólitos inibitórios sobre patógenos intestinais em amostras de soro do queijo comercial minas frescal industrial e de amostras de soro de coalhada, mussarela, minas frescal artesanal. No decorrer da execução do trabalho houve a inclusão do chá de kombucha produzido de forma artesanal nas análises, visto que é uma bebida saudável e segundo Bruschi et al. (2018) o chá de Kombucha tornou-se uma bebida muito popular nestes últimos anos por causa dos seus potenciais efeitos benéficos à saúde humana.

\section{MATERIAL E MÉTODOS OU METODOLOGIA (ou equivalente)}

Foram utilizadas, amostras de soro de queijos minas frescal, coalhada, mussarela e kombucha, elaboradas de forma industrial e artesanal. Foi realizado nas amostras o teste de presença de microrganismos. No teste de anatagonismo, foi utilizado o método de cultura mista descrito por Mamédio, (2017), e o método de difusão em disco, técnica descrita em 1966, por Bauer e Kirby (ANVISA, 2008).

As enterobactérias (Staphylococcus aureus, Escherichia coli e Salmonella sp) foram ativadas, utilizando o meio de cultura Brain Heart Infusion (BHI), incubadas a $35^{\circ} \mathrm{C}$ por 48 horas, após crescimento, foi realizado a coloração de Gram (figura 1), confirmando que são bactérias Gram-negativas. Em seguida foram preparadas suspensões em solução salina das culturas de Staphylococcus aureus, Escherichia coli e Salmonella sp., equivalente a 0,3 da escala Mc Farland. No método de cultura mista, alíquota de $10 \mu \mathrm{L}$ dessa suspensão foi inoculada em $1 \mathrm{~mL}$ de cada amostra de soro e $1 \mathrm{~mL}$ 
da bebida kombucha. As misturas de bactérias enteropatógenas com as respectivas amostras, foram acondicionadas no refrigerador por $24 \mathrm{~h}$. Cada uma das misturas obtidas foram semeadas em placas de Petri contendo meio ágar nutriente e incubadas a $35^{\circ} \mathrm{C}$ por 48h. Após este período foi observado o crescimento dos enteropatógenos.

No método de difusão em disco foram preparadas suspensões das culturas de bacterias patogênicas, como descrito anteriormente. Em seguida, essa suspensão com os respectivos enteropatógenos, foram semeadas no meio Ágar Muller Hinton por superfície total com swab estéril, incubadas por $35^{\circ} \mathrm{C}$ por 30 minutos. Foi colocado na placa recém-semeadas com as enterobactérias, com auxilio de uma pinça estéril, discos de papel-filtro estéreis de aproximadamente $6 \mathrm{~mm}$ de diâmetro, impregnados com os soros e com a bebida kombucha. As placas foram Incubadas a $35^{\circ} \mathrm{C}$ por 48 horas. Após esse período foi realizada através da observação a leitura dos halos de inibição. Em seguida foi realizada a análise de identificação e caracterização de bactérias láticas (AXELSSON, 1993) que são coloração de Gram e teste de catalase.

\section{RESULTADOS E/OU DISCUSSÃO (ou Análise e discussão dos resultados)}

As amostras de soro de queijo mussarela artesanal, minas frescal artesanal e industrial e bebida kombucha artesanal, utilizadas, apresentaram colônias bacterianas com características preliminares de bactérias láticas: resultado negativo para o teste de catalase, sendo bacilos Gram-positivas pela coloração de Gram (Figura 2). Apenas a amostra do soro da coalhada artesanal apresentou, além das bactérias láticas, leveduras e outros tipos de bactérias, com características diferentes de bactérias láticas, a exemplo do teste de catalase positivo (figura $2 ; \mathrm{d}$ ). Os resultados do teste de antagonismo podem ser observados na Tabela 1 .

Tabela 1. Testes de antagonismo entre amostras de soro de queijo e amostra de bebida fermentada (kombucha) sobre enteropatógenos.

Teste de Antagonismo

\begin{tabular}{|c|c|c|}
\hline Amostras & $\mathrm{pH}$ & Staphylococcus aureus $\quad$ Escherichia coli Salmonella sp \\
\hline $\begin{array}{l}\text { Soro Minas Frescal } \\
\text { industrial }\end{array}$ & 5,89 & \\
\hline $\begin{array}{l}\text { Soro Minas Frescal } \\
\text { artesanal }\end{array}$ & 5,81 & Não houve inibição em ambos os métodos \\
\hline $\begin{array}{l}\text { Soro mussarela } \\
\text { artesanal }\end{array}$ & 5,26 & \\
\hline Soro coalhada artesanal & 4,26 & \\
\hline Kombucha artesanal & 2,84 & $\begin{array}{l}\text { Não houve inibição na técnica da difusão em disco, } \\
\text { mas apresentou inibição na técnica da cultura mista }\end{array}$ \\
\hline
\end{tabular}

Ao analisar os resultados que constam na tabela acima, do teste de antagonismo verifica-se que as bactérias láticas presentes nas amostras de soro não inibiram as bactérias patogênicas (Staphylococcus aureus, Escherichia coli e Salmonella sp) em nenhum dos métodos aplicados. Entretanto, na bebida kombucha artesanal houve inibição dos três patógenos intestinais (Staphylococcus aureus, Escherichia coli $e$ 
Salmonella sp), no teste de cultura mista (figura 3), mas não na técnica de difusão em disco.

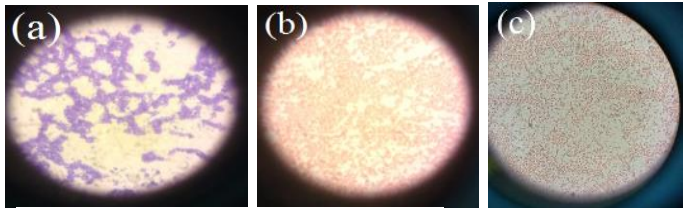

Figura 1: Coloração de Gram (a) Staphylococcus aureus, (b) Escherichia coli, (c) Salmonella sp.
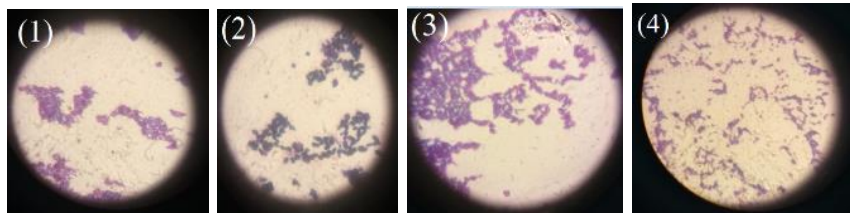

Figura 2: Coloração de Gram das amostras de soro (1) Minas frescal artesanal; (2) Coalhada artesanal; (3) Mussarela artesanal; (4) Minas Frescal Industrial.
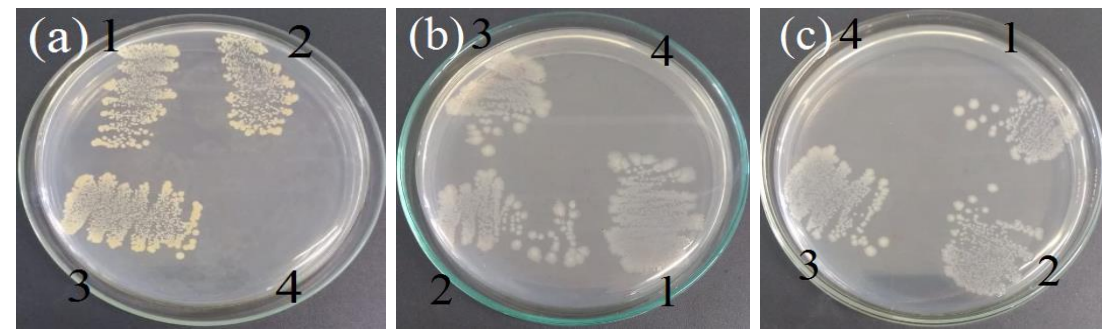

Figura 3: Teste de Antagonismo (cultura mista). (a) Staphylococcus aureus; soro minas frescal artesanal (a.1); coalhada (a.2); Mussarela (a.3 ); kombucha (a.4); (b) Escherichia coli; soro minas frescal artesanal (b.1); coalhada (b.2); Mussarela (b.3 ); kombucha (b.4); (c) Salmonella sp; soro minas frescal artesanal (c.1); coalhada (c.2); Mussarela (c.3); kombucha (c.4).

Segundo Hütt et al. (2006) apud Sant'anna (2015) observaram relação positiva entre o antagonismo a enteropatógenos e a produção de ácido lático, assim como relação inversa entre o valor de $\mathrm{pH}$ do sobrenadante com a atividade antagonista. Dessa forma, uma possível explicação para o efeito antagônico pode ser baseada na produção de ácidos orgânicos e/ou de bacteriocinas que possuem melhor atividade inibitória em meios ácidos. Como mostra na tabela 1 a kombucha apresentou um $\mathrm{pH}$ de 2,8, sendo bastante reduzido se comparados com as amostras de soro. Esses dados podem corroborar o efeito inibitório da kombucha artesanal frente às bactérias patogênicas (Staphylococcus aureus, Escherichia coli e Salmonella sp).

Apesar do presente trabalho, não ter apresentado efeito inibitório sobre os enteropatógenos, várias pesquisas demonstram o contrário: Sant'anna (2015), demostram que "As amostras de Lactobacillus spp. e Pedioccocus acidilactici apresentaram resultados satisfatórios nas análises in vitro, sendo resistentes aos ácidos e sais biliares, exercendo atividade antagônica contra microrganismos patogênicos e apresentaram percentuais satisfatórios de resistência aos antimicrobianos, de acordo com a literatura. Além do trabalho de Costa et al. (2012) que trás relatos do efeito antagônico de BAL sobre patógenos comuns em alimentos.

Pereira e Gómez (2007) apud Costa et al. (2012) relataram inibição de E. coli e S. aureus por L. acidophilus. Lahtinem et al. (2007) observaram inibição de S. aureus, Salmonella spp. e E. coli por linhagens de Bifidobacterium, Uraz, Simsek e Maras (2001) e Guedes Neto et al. (2005) relataram a inibição de microrganismos indicadores por BAL isoladas de queijo artesanal e leite cru. Vaughan, Caplice e Looney (1994); Brashears e Durre (1999) e Chioda et al. (2007) também observaram ação antagonista de algumas BAL contra Salmonella spp. e E. coli O157:H7, S. aureus, Listeria inócua e Pseudomonas fragi. 
Nos soros presentes de queijo e coalhada, a acidez não foi muito elevada, razão pelo qual não apresentou inibição em nenhum dos patógenos testados. Já no caldo fermentado do Kombucha foi notado o efeito inibitório sobre os enteropatógenos, corroborando com vários autores que a alta acidez presente nas bebidas fermentadas correspondem a um dos principais princípios ativos da inibição.

No trabalho de Bruschi, et al. (2018) o chá de Kombucha pode ser usado para prevenir infecções malasseziais e outras doenças do trato gastrointestinal. Pode-se assim comparar o efeito inibitório observado no presente trabalho.

\section{CONSIDERAÇÕES FINAIS (ou Conclusão)}

Apesar do foco principal deste trabalho ter sido a avaliação da ação inibitória do soro resultante da elaboração do queijo Minas frescal e coalhada, estes não mostraram resultados esperados, já que possuem uma grande população de bactérias láticas. Mas com a inclusão da bebida Kombucha esta ação pode ter sido demonstrada, sugerindo que o princípio ativo mais eficaz das bactérias inibitórias sobre os enteropatógenos, está na produção de ácidos orgânicos.

\section{REFERÊNCIAS}

ANVISA. Agencia Nacional de Vigilância Sanitária. Interpretação de dados microbiológicos. Métodos para o TSA - Teste de Suscetibilidade aos Antimicrobianos. Disco-difusão. AT Mracional, 2008.

BRUSCHI JS, Sousa RCS, Modesto KR. O Ressurgimento do Chá de Kombucha. Rev Inic Cient Ext. 2018; 1(Esp): 162-8.

COSTA, G. N. et al. Atividade Antimicrobiana de Lactobacillus e Bifidobacterium frente a microrganismos patogênicos “ in vitro". Semina: Ciências Agrarias, Londrina, v 33, n. 5, p. 1839- 1846, set/out. 2012.

FARINHA, Luiz Rogerio Ludwig. Efeito da composição de bactérias lácticas e da suplementação do soro de leite na cinética de acidificação, crescimento celular e produção de nisina. Universidade de São Paulo,2016.

MAMÉDIO, Ilana Maciel Paulo atividade antifúngica de cepas de bactérias láticas e extratos de casca e coroa de abacaxi sobre fusarium guttiforme nirenberg \& o'donnell. Dissertação Programa de Pós-graduação em Recursos Genéticos Vegetais da Universidade Estadual de Feira de Santana, 2017.

MENEZES, et al. Microbiota e Conservação do Leite. Revista Eletrônica em Gestão, Educação e Tecnologia Ambiental -REGET. Ed. Especial Mai. 2014, p. 76-89.

SANT'ANNA, Felipe Machado de. Lactobacillus e Pediococcus de silagem, água, leite, soro fermento endógeno e queijo Minas artesanal da região de Campo das Vertentes: isolamento, identificação molecular, avaliações in vitro e in vivo do potencial probiótico. Belo Horizonte Escola de Veterinária 2015.

VIEIRA, Andressa Prado. Aplicação de bacteriocinas de bactérias lácticas para controle de Listeria monocytogenes em queijo Minas Frescal preocessado pelo método de acidificação direta. Universidade de São Paulo, Escola Superior de Agricultura "Luiz de Queiroz" 2011. 